
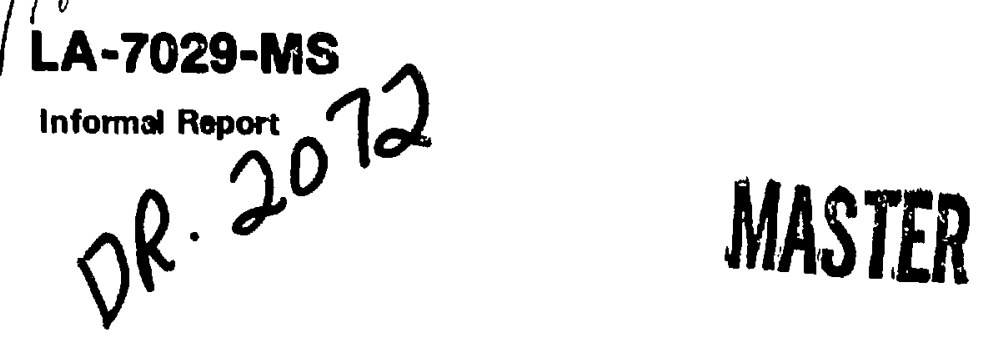

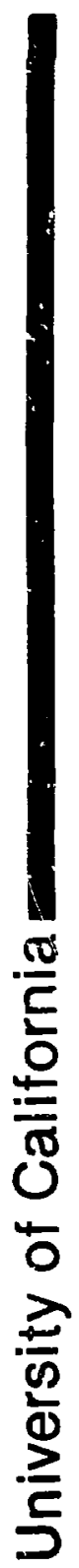

Fiber Optic Utilization at the Nevada Test Site

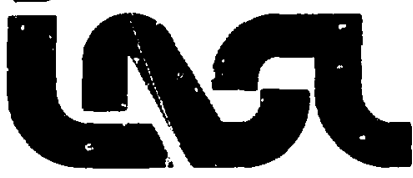


LA-7029-MS

Informal Report

UC-38

Issued: Novemter 1978

\title{
Fiber Optic Utilization at the Nevada Test Site
}

\author{
P. B. Lyons \\ J. E. Golob \\ L. D. Looney \\ F. E. Robichaud* \\ M. A. Nelson* * \\ T. J. Davies* *
}
Thus exporl was prepared is an sccount

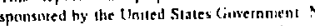
Uimied States now the Uniled States Depia
linerg. nor any of their emplayers. nur an

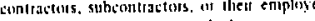
any warranty, express of implied, or assunie

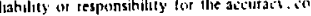
or use fulness of any information, ope aralus.
process disclinsed, ir represents that its use
infringe privately owned nghts.

-EG\&G, Inc., P. O. Box 809, Los Alamos, NM 87544.

* EG\&G, Inc., Santa Barbara Division, 130 Robin Hill Road, Goleta, CA 93017.

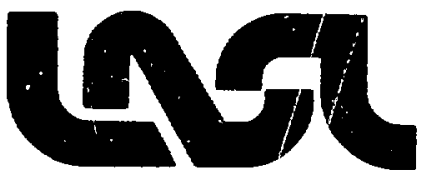




\title{
FIBER OPTIC UTILIZATION AT THE NEVADA TEST SITE
}

\author{
by \\ P. B. Lyons, J. E. Golob, L. D. Looney, R. E. Robichaud, \\ M. A. Nelson, and T. J. Davies
}

\begin{abstract}
Optical fiber cables have been successfully used for 100-MHz analog data transmission during an underground nuclear test at the Nevada Test Site. Two 700-m Corning Corguide cables were used to provide thirteen single fiber data channels from the vicinity of the underground detonation, 350 meters below ground level, to recording instrumentation, 350 meters from the downhole shaft. No fiber performance degradation was observed during the extensive procedures used to seal the shaft. These procedures included backfilling the shaft with layers of sand and gravel, as well as poured epoxy plugs. Techniques were developed for interr.al sealing of the Corguide cable to prevent any possible radioactive gas flow through voids within the cable. The effects on optical fiber 3 of intense, pulsed neutron and gamma irradiation were studied. Specialized tools, including a system for location of faults or breaks in the optical fibers, were developed. The success of this first test will allow consideration of fiber optic cables for future nuclear tests as well as for other applications involving extremely rough handling in field enviroliments.
\end{abstract}

\section{INTRODUCTION}

At the Nevada Test Site (NTS) nuclear explosive experiments have been conducted for over 25 years. These testa have demanded state-of-the-art diagnostic systems constructed by multidisciplinary scientific teams. Technologies represented include nuclear physics; high- speed electronics; high-speed, multichannel data recording; high-speed data transmission; advanced computer sciences; and deep drilling techniques. These diverse specialties must function together in the difficult environment of a nuclear event to acquire a maximum data set from each test, particularly with the greatly restric- ted number of tests conducted in recent years. Advances in any one of these areas of technology can impact the data gathering process.

This report discusses the first NTS test of fiber optic technology, a state-of-the-art solution to one aspect of weapon testing technology. Fiber optics have the potential to revolutionize the capability to transmit quantities of data at speeds far above those of coaxial cable systems. However, the fiber optic systems available commercially today are not directly suitable for weapon testing. Therefore, tools and capabilities were developed within cur Laboratorios to field the test. The successful project 
demonstrated the feasibility of fiber optic utilization at NTS and represented one of the most severe applications (from an environmental standpoint) of fiber optics to date. Our results may allow experimenters to contemplate application of fiber optics in different, but equally severe, environments.

\section{OVERVIEW OF A TYPICAL TEST}

Tests are conducted at the bottom of deep holes (or, infrequently, in deep tunnels). ${ }^{1}$ Hole depths range from $200 \mathrm{~m}$ to $1 \mathrm{~km}$. Hole depth is a function of many parameters (yield, geologic siratu, type of experiments, etc.) and is calculated with great conservatiom to preclude totally any release of radioactive material. Hole diameters range from 90 to 225 $\mathrm{cm}$.

The nuclear device is located at the bottorn of a cylindrical steel frarnework, or rack. All experiments and assosiated support hardware are mount ed on the rack. Coaxial cables connect the experiments to recording stations located uphole. Various collimated lines of sight connect the experiments to the nuclear device. Experiments may be as close as $50 \mathrm{~cm}$ from the device center, or as far as the rack length (up to $70 \mathrm{~m}$ ). The entire rack, with its attached cables, is lowered to the bottom of the hole. A schematic view of a typical rack is shown in Fig. 1 .

After the rack is lowered, an extensive procedure is followed to seal the shaft. Layers of sand, gravel, and spoxy are used to stem the experiment. Exact details of the stemming plan must be approved in arvance by the Containment Evaluacion Panel, composed of members from several agencies including ERDA (currently DOE), USGS, etc. The hole is completely filled, thus exposing cables to the stemming material over long distances. The excellence of the containment procedure is such that absclutely no leakage has occurred for any test within the past seven years.

All cables must either be constructed sn as to be continuously gas tight, or must have discrete gastight seals inserted at intervals. The discrete gastight sea's are inserted at appropriate positions so that the seal is in a stemming section of poured epoxy (typically $3 \mathrm{~m}$ in length). To be certified for NTS use, a cable must withstand $0.86 \mathrm{MPa}$ (125 psi) for 24 hours without $a$ leak over a 3-m gauge length.

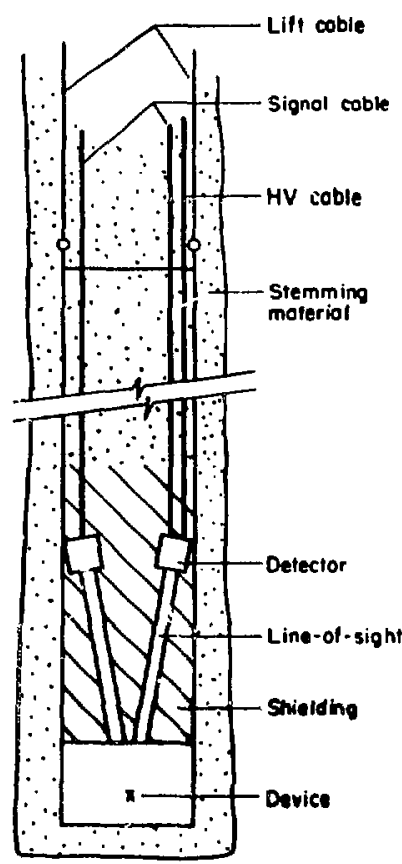

Fig. 1.

Schematic of a typical NTS rack geometry. Detector distances range from $50 \mathrm{~cm}$ to $70 \mathrm{~m}$ from the device.

\section{II. FIBER OPTIC ADVANTAGES AND DIS- ADVANTAGES FOR NTS}

Fiber optics offer significant bendwidth improvement over conxiel cable. Table I compares the 3-dB frequency response, procurement costs, and weights of several standard NTS coaxial cebles to fiber optics over a one-km distance. The bulky coax cables incur additional handling costs approximately equal to their procurement costs. At the time of the test, a gas blocking capability had been developed only for Corning Corguide - thus only Corguide is listed in Table I. (Use of Corning cable does not imply endorsement of that product for future tests by $D O E$ or LASL.) In addition to bandwidth, weight, and cost advantages, other advantages include handling ease, cross-sectional area, and EMP isolation. With an annual LASL NTS cable budget near $\$ 5 \times 10^{\circ}$, the cost advantage alone is sufficient to justify interest in fiber optics. 
TABL $\mathrm{I}$

\begin{tabular}{|c|c|c|c|c|c|}
\hline \multicolumn{6}{|c|}{ Coax and Fiber Diuperalon } \\
\hline & & & Eansipaso, $\mathrm{MHz}{ }^{(a)}$ & Appr. Cost $(b, c)$ & Weight (kg/kn) \\
\hline 8 & $\begin{array}{l}1.3-\mathrm{cm} \\
2.2-\mathrm{cm} \\
4.1-\mathrm{cm}\end{array}$ & $\begin{array}{l}\text { Foam Dlelectric } \\
\text { Foam Dielectric } \\
\text { Foan Dielectric }\end{array}$ & $\begin{array}{r}1.3 \\
3.4 \\
10.9\end{array}$ & $\begin{array}{r}\$ 1.80 \\
3.94 \\
12.20\end{array}$ & $\begin{array}{r}220 \\
620 \\
2100\end{array}$ \\
\hline$\underset{\mathbf{H}}{\stackrel{H}{*}}$ & Corguide & Cable Type 1302 & 200 & 2.25 & 4.2 \\
\hline
\end{tabular}

(a) 3-dB fre? for 1-ke length

(b) per m-chaninel

(c)based on most recent procurement

Disadvantages are kiso prese operations with coax are, at present, far from routine with fibers. To proceed with the test, LASL and EG\&G developed skills for the necessary operations. The relative fragility of fiber optics compsted to conx was of great concern, especially in the stemming operation. New detector systems, which provide an analog light output, may be required to replace present systems that produce electrical anslog outputs. Background problems observed with coax were expected to be different for fibers. Deta existed that demonstrated radiation-induced transient absorption and luminescence in optical fibers. ${ }^{3}$

\section{V. GOALS OF THE FIRST TEST}

Two specific goals were established for the first NTS test:

1. To demonstrate the feasibility of fiber optic utilization in the NTS environment, and

2. To determine the neutron-induced transient effects in two types of low-loss fiber.

In support of goal (1), development of gas blocking techniques as well as other basic support techniques was required. For goal (2), an extensive series of laboratory radiation tests was initiated. However, all laboratory tests used only $x$-rays or electrons for transient studies. No laboratory neutron sources are available with pulse widths (a few tens of ns) or outputs approaching downhole fluences. Long-term neutron effects had been studied, and the observed effects were comparable (when compared in terms of ionizing dose) to x-ray and electron irradiations. The pulsed neutron tests required a nuclear explosion source.

Both goals were achieved; however, this report will address only the first goal. Laboratory work in support of the second goal has been published" as well as additional work from other laboratories. Data on neutron effects will be published separately.

\section{EXPERIMENT DESIGN}

Two 700-m Corguide cables were used to carry optical data from the rack area $(350 \mathrm{~m}$ below ground level) to a station located $350 \mathrm{~m}$ from ground zero. Each cable was gas blocked at two places; each block was within an epoxy layer in the shaft. In the experimental station, each fiber (13 in all), was inserted into an optical detector package. (Corning guarantees six of the seven Corguide fibers to be within specification. The two cables as delivered had six and seven usable fibers, respectively.) Wavelength-dependent beam splitters and interference filters isolated two wavelength bands-at $600 \mathrm{~nm}$ and $800 \mathrm{~nm}$. Photomultipliers recorded the light and oscilloscopes recorded the tube outputs.

Within the downhole rack, two experirnentel stations with different neutron and gamma radistion exposure levels were constructed. Two types of fiber 
(germanium-doped graded index and borosilicatecicid pure fused-silica step index) were exposed. Both luminescence and absorption measurements were conducted on each type. For luminescence measurements, the fiber end was shielded from any light sources. For absorption measurements, the fiber end viewed a pulsed flashlamp. The lamp providud a light leve' at zero time against which absorption could be observed.

The fihers used within the rack were spliced to the uphole cables within the flashlamp enclosure. Additiona! splices in the flashlamp box attached inrack fibers to fiber pigtails from the flashlamp, for those cases where flashlamp exposure was required. The uphole cables were one continuous run without splices. Overall system bandpass was about 100 MHz. A schematic view of the experiment is shown in Figs. 2 and 3.

\section{ENGINEERING DEVIELOPMENT}

\section{A. Gas Blocks}

Any optical cables used at NTS must meet the existing gas blockage requirements for coaxial cables. Studies of optical cable available in 1976 showed gas transmission at low pressures. Since loose cable structures result in minimum additional optical attenuation due to microbending, this result was experted.

Several techniques were considered for gas blocks. A useful gas block had to be amenable to field installation at any location along a continuous cable. Ideally, a block would not comprumise the tensile strength or durability of the cable. Optical attenuation of the block should be es low as possible.

Corguide cable was selected for various reasons including the ease with which the etranded Kevlar strength members could be accessed without danger to the optical fibers. (Sea Fig. 4 for a cross-sectional view of Corguide. ${ }^{\circ}$ ) In Corguide, each of seven fibers is enclosed in a urethane buffer layer. Interstitial spaces exist between the fiber and the buffer and among the seven buffering sleeves. Initial tests demonstrated that a combination of temperature and pressure could compress the urethane buffer coatings to stop gas leakage around the fibers or buffer layers. The stranded Kevlar member: were not

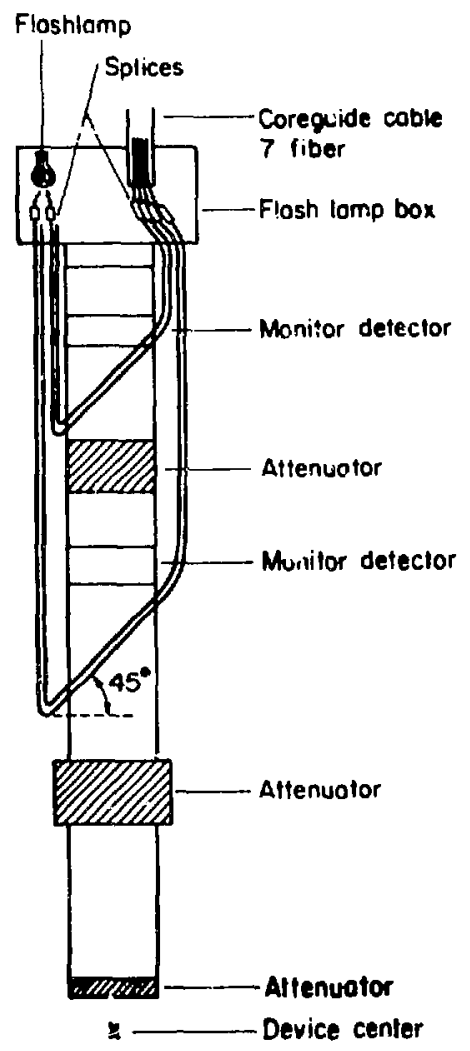

Fig. 2.

Schematic of the line-of sight used in the fiber tests. The flashlamp box was located $14 \mathrm{~m}$ from the device. Two fiber exposure stations were located at 6 and $9 \mathrm{~m}$ from the device. Attenuators adjusted the fluence to desired values. Fibers were oriented at approximately the Cerenkov angle.

sealed by this technique. Early techniques involved cutting and removal of the Kevlar members for a short distance. This provided a gas seal but compromised the cable strength. This technique was abandoned subsequently.

The procedure finally adopted involved use of a specially shaped block (Fig. 5) into which a $10 \mathrm{~cm}$ length of cable was compressed under controlled temperature and pressure conditions, thereby sealing sll leak peths except the strength member. Just outside the block area, the outer jacket was scraped away to expuse $1 \mathrm{~cm}$ of strength nember. The cable 


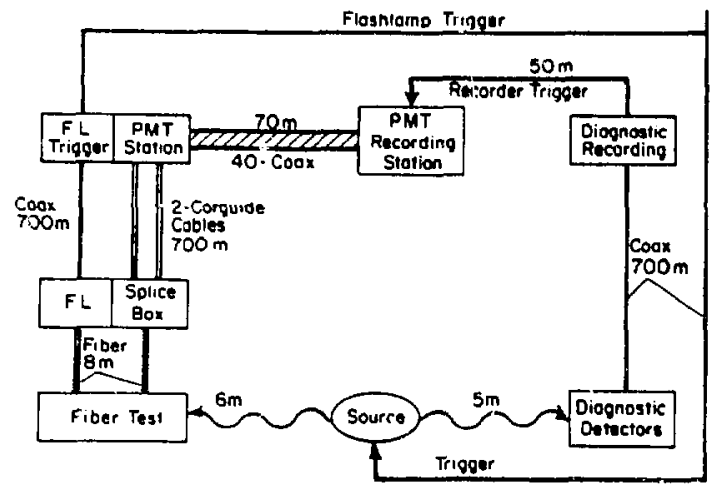

Fig. 3.

Cable diagram of the experiment. Note that 40 coax cables were used to transmit electrical pulses from photomultipliers (PM) which vicwod the fibers in two Corguide cables. The flashlamp (FL) was triggered from the device firing signal. The PM recorders were triggered from other diagnostic systems. Accurate timing between fibers and coax was essential.

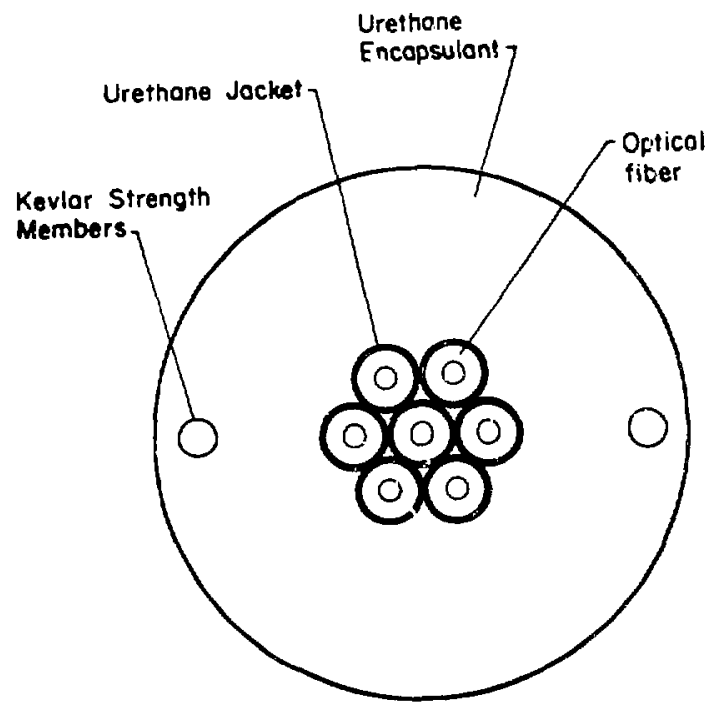

Fig. 4.

Cross section of Corguide Cable. Paths for gas leakage exist within the stranded strength members, between the fiber and urethane jacket, and between the seven jackets.

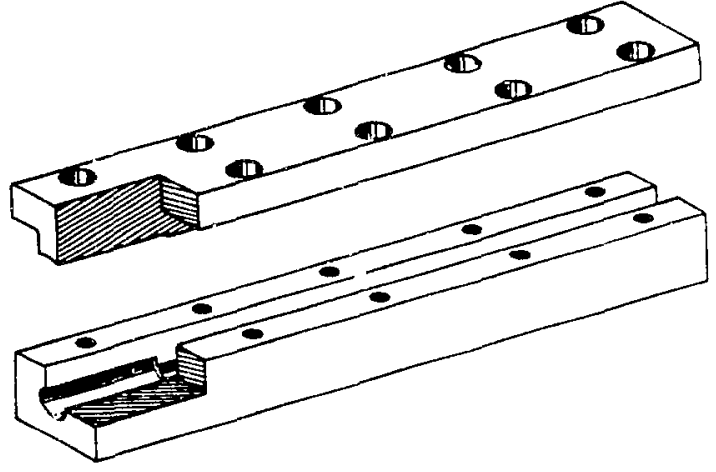

Fig. 5.

Cut-away view of an aluminum gas block. Total length is $15 \mathrm{~cm}$, with the central $10 \mathrm{~cm}$ compressed to seal portions of the Corguide cable.

and metal block were then potted into a short (25cm) cylinder of low-viscosity epoxy (Furane Epocast 223). The epoxy wicked into the stranded strength members and sealed them.

The resulting gas block was leakfree at $0.86 \mathrm{MPa}$ (125 psi) for 24 hours and $3.6 \mathrm{MPa}(500 \mathrm{psi})$ for short times. Since the strength members were intact, cable strength was not compromised. After adjustment of block dimengions, blocks with optical attenuation below $0.2 \mathrm{~dB}$ were achieved.

\section{B. Connectorg and Splices}

No commercial source for connectors existed in late 1976 (to the authors' $\mathrm{k}^{\mathrm{r}}$;wledge) except for connectors sold as part of larger systems. Since 25 dow whole connections were needed, either splices or connectors were mandatory. In the p.bsence of connectors, several splice techniques were tested including the "three drill-rod" technique, ${ }^{7}$ the "loosetube" technique, and fiber fusing., ${ }^{8,10}$ Under field conditions, the last two techniques were preferred. The latter technique was not perfected in time and the loose-tube method was adopted for this test. Splices were required to Corning graded-index (75$\mu \mathrm{m}$ core-diameter) fiber from both similar fibers and from borosilicate-clad pure fused-silica step-index 
fibers [from Fiber Communications, Inc. (FCI )]. Both fibers had $125-\mu \mathrm{m}$ outer diameter. Core diameter of the FCI fiber was $78, u \mathrm{~m}$.

In the louse-tube method, the two fiber ends are first cleaved and then manipulated until they both seat into one corner of a short glass tube with a square internal hole. A He- $\mathrm{Ne}$ laser was used to irradiate one end of each fiber as it was spliced. A definitive signature of proper fiber alignment was provided by an abrupt extinction of scattered light from the joint. For Corning-to-Corning joints, an a verage loss of $0.46 \mathrm{~dB}$ was obtained. For FCl-toCorning joints, average loss was $2.8 \mathrm{~dB}$.

A fiber cleaving tool was fabricated that provided controlled tension over a $5.7-\mathrm{cm}-$ radius bend together with a system for carbide scribing the fiber. ${ }^{11,12}$ Resulting fibel ends were usually within $3^{\circ}$ from the normal to the fiber optical axis.

\section{Fiber Timing}

Utilization of analog, multichannel data requires an accurate system for time difference measurements between different optical channels as well as between coaxial cable and optica! channels. In addition, a system for locating cable breaks was needed. Both requirements are met by a time domain reflectometer. Two units were built following the principle outlined in $r$ ig. $6 .^{13}$ These units were similar in principle to those described subsequently by Personick in Ref. 14. In these units stray lighi coupling of the injected pulse into the photodetecter can satirate it, reducing system sensitiviy and ccmplicating detection of early time return pulses. Personick used a gated photomultiplier to eliminate the tube saturation. The design of Fig. 6 relies on careful attention to polarization phenomena to greatly suppress stray light on the photomultiplier. An RCA 31034 tube was used. In Fig. 7 reflections from the downhole system are seen. Two splices and the fiber end are clearly visible. Timing to 1-ns accuracy was provided by the units.

\section{Cable Durability and Handling}

On the test, the Corguide was sposled off and taped to the outside of the main coaxial cable bundle. The main coaxial cable bundle was secured

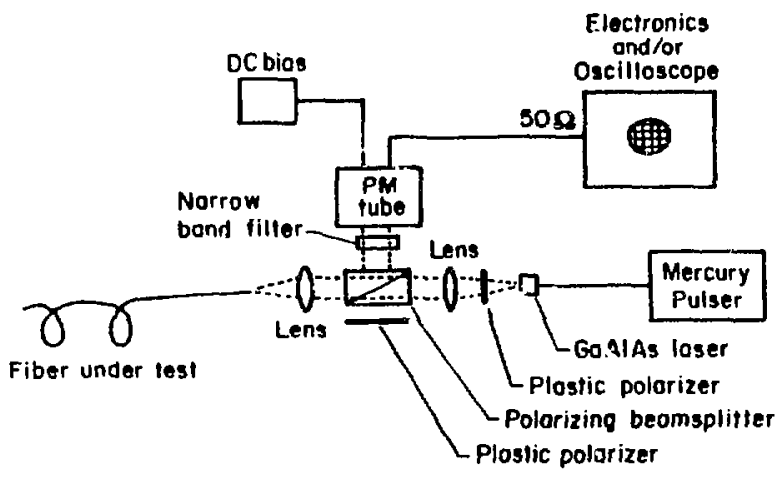

Fig. 6.

Schematic view of the time domain reflectometer. Stray light from the injected pulse yields a start, or trigger, pulse in the photomultiplier (PM) tube. Reflected return pulses are viewed by the same tube. Carefui attention to poirarization components results in a minimum overload of the PM on the start pulse. The fiber return pulse is unpolarized despite injection of polarized light.

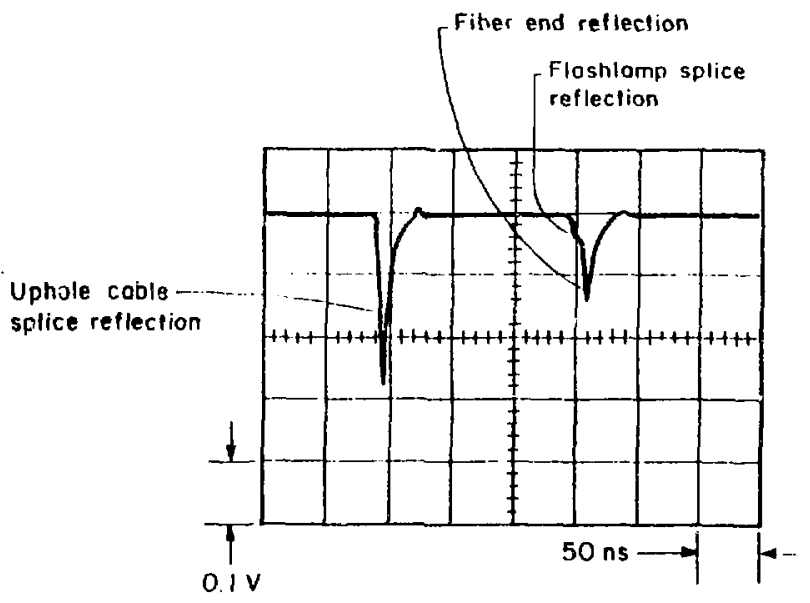

Fig. 7.

Reflected return pulses from the downhole system displayed with a delayed suleep presentation. Two splices plus the fiber end are readily observable. Note that the splice onto a short $(45-\mathrm{cm})$ fiber pigtail leading to the flashlamp is readily observable even after twoway propagation through $700 \mathrm{~m}$ of fiber. 
with tight wire and tape wraps to the main support harness. The Corguide was kept outside of the wire wrap to eliminate any possibility that the wire would slice through the Corguide. This procedure placed the optic cable in full contact with the stemming material. No difficulties with the cable were experienced on the actual test.

\section{E. System Bandwidth Measurement}

The electron linac at EG\&G, Inc., in Santa Barbara, California, was used to document time response of all components. The linac delivers 50-ps wide, single pulses of electrons at 360 pps with peak currents up to $10 \mathrm{~A}$ and energy variable from 1 to 27 $\mathrm{MeV}$. Response of photomultipliers in the system was determined using Cerenkov light from a Lucite radiator in the electron beam. The photomultipliers, RCA type 4840 and 4832 , showed FWHM of 1.8 ns and 2.1 ns, respectively. Fiber pulse dispersion was determined by allowing the electron beam to irradiate the fiber at the Cerenkov angle, thereby injecting a broad spectrum light pulse into the fiber. The light was detected upon exit from the fiber by a Varian static cross-field photomultiplier with an InGaAsP photocathode. (Response of the photomultiplier was measured as 160 ps FWHM.) Narrow band filters were used to restrict material dispersion effects. Table II shows typical data for a few fibers. All fibers far exceeded the nominal $400-\mathrm{MHz}$ specification by Corning.
Reference 15 explains the experimental details of a typical measurement and includes a discussion of the computer-of-average transients, sampling recorder system.

'Tlie' handwidth limiting elements in the system were the photomultipliers and the coax cables connecting the tubes to oscilloscopes. System bandwidth was about $100 \mathrm{MHz}$.

\section{F. DC Attenuator System}

Several components of the system (splices, gas blocks, and the (jiber) introduced optical attenuation into the experiment. To document these effects as a function of wavelength, the system shown in Fig. 8 was developed. The numerical aperture of the launched light was variable. Cladding mode strip. pers were used for all measurements. Tiber attcnuation values were similar to data supplied by Corning. On the two Corguide cables used, attenuations ranged from $1: 3.5$ to $20.1 \mathrm{~dB} / \mathrm{km}$ at $6000 \mathrm{~A}$ and 5.8 to $12.0 \mathrm{~dB} / \mathrm{km}$ at $8000 \mathrm{~A}$.

\section{SUMMARY}

The first fiber optic experiment at the Nevada Test Site satisfied the goal of a feasibility demonstration for optical fibers in that demanding environment. The various subsystems described in this report all functioned together correct!y. This

TABLE II

\begin{tabular}{|c|c|c|c|}
\hline \multicolumn{4}{|c|}{ Measured Fulse Dispersion* } \\
\hline Fiber & Wave lengt is $(\mathrm{nm})$ & Bandwtdth $(\mathrm{nm})$ & FWHM (ns) \\
\hline \multirow[t]{4}{*}{1} & 600 & 11 & 2.56 \\
\hline & 600 & 1.5 & .44 \\
\hline & 800 & 11.3 & 1.12 \\
\hline & 800 & 1.5 & .59 \\
\hline \multirow[t]{4}{*}{4} & 600 & 11 & 2.69 \\
\hline & 600 & 1.5 & .37 \\
\hline & 800 & 11.3 & 1.18 \\
\hline & 800 & 1.5 & .66 \\
\hline
\end{tabular}

*Over $800 \mathrm{~m}$, cable was later trtmmed to $700 \mathrm{~m}$. 


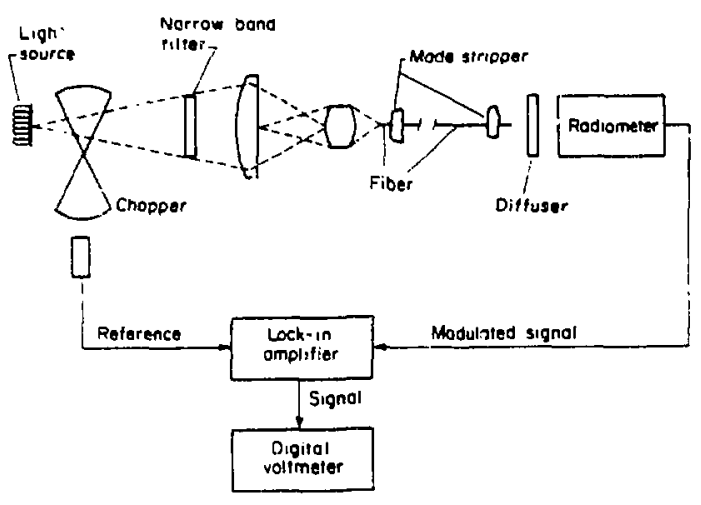

Fig. 8.

The DC attenliation system used for characterization of the optical attenuation of each system component.

first test has allowed considerations of a variety of experiments at NTS utilizing the unique properties of fiber optics. Component evaluation and development has continued with emphasis on connectors. Fast radiation-to-light converters are under study for direct coupling to fibers. ${ }^{10}$ A video optical data link has been successfully fielded at NTS by the Lawrence Livermore Laboratory. ${ }^{17}$ Readout systems for fibers using streak tubes are under development. ${ }^{10}$ Full utilization of the benefits of fiber optics for NTS diagnostics (or in any other diagnostic environment with difficult bandwidth, EMP, etc., requirements) will require many years. But the future of optical fibers for such difficult applications can be predicted to hold great promise.

\section{ACKNOWLEDGEMENTS}

Many individuals at our Laboratories contributec to this successful test. Individuals deserving of special mention include J. C. Hopkins, P. W. Keaton, D. S. Metzger, S. Depp, A. Lieber, B. Killian, E. M. Hidalgo, J. Allen, R. Hooker, D. Bartram, T. L. Elsberry, J. Lindahl, and D. Roberts of LASL; C. King and P. Olivas of EG\&G, Los Alamos; R. Seno, R. Beam, J. Bearce, and J. Madrid of EG\&G, Las Vegas; and N. J. Norris and L. B. Hocker of EG\&G, Santa Barbara. Many interactions with personnel at the Lawrence Liver- more Laboratory contributed to the success of the test. Special thanks are due to $\mathrm{H}$. Kohler, $\mathrm{D}$. Jones, and L. Multhauf of LLL for a major cont ribution to design of the final gas block package.

Studies at EG\&G Santa Barbara funcind by the R\&D Program of the Nevada Operations Office of the Department of Energy were instrumental in demonstrating the potential of optical fibers ior NTS applications.

\section{REFERENCES}

1. W. P. Wolff, "A Typical LASL Underground Nuclear Test," LASL Mini-Review 77-2, Los Alamos Scientific Laboratory (June 1977).

2. P. L. Mattern, L. M. Watkins, C. D. Skong, J. R. Brandon, and E. H. Barsis, "The Effects of Radiation in the Absorption and Luminescence of Fiber Optic Waveguides and Materials, "Sandia Report SAND 74-8622 and IEEE Trans. Nuc. Sci. NS-21, p. 81, No. 6 (1974).

3. L. M. Watkins and E. H. Barsis, "Absorption Induced in Glass and Plastic Fibers by $14 \mathrm{MoV}$ Neutrons," Sandia Report SAND 75-8714 (June 1976).

4. J. E. Golob, P. B. Lyons, and L. D. Looney, "Transient Radiation Effects in Iow Loss Optical Waveguides," 1977 IEEE Nuclear and Space Radiation Effects Conference, Los Alamos Scientific Laboratory internal document (July 1977).

5. C. D. Skoog, "Summary of Radiation-Inciuced Transient Absorption and Recovery in Fiber Optic Waveguides," Sandia Report SAND 76 8056 (November 1976).

6. Corguide Cable Bulletin No. 4, Corning Glassworks, 1976.

7. Corning Application Note-"Procedure for Splicing Optical Waveguides," A. Fairaizl, Corning Glass Works private communication (1э76). 
8. C. M. Miller, "Loose Tube Splices for Optical Fibers," Bell Syst. Tech. J. 54, p. 1215 (1975).

9. D. L. Bisbee, "Splicing Silica Fibers with on Electric Arc," Appl. Opt. 15, p. 796 (1976).

10. Y. Kohanzadeh, "Hot Splices of Optical Waveguide Fibers," Appl. Opts. 15, p. 793 (1976).

11. D. Gloge, P. W. Smith, D. L. Bisbee, and E. L. Chinnock, "Optical Fiber End Preparation for Low-Loss Splices," Bell Syst. Tech. J. 52, p. 1579 (1973).

12. Corning Application Note AN-2, "Low-Loss Optical Waveguide End Preparation," Corning Glassworks, 1975.

13. M. A. Nelson, T. J. Davies, P. B. Lyons, J. Golob, and L. Looney, "A Fiber-Optic Time-
Dorıain Reflectometer," submitted to 1978 SPIE Technical Symposium.

14. S. D. Personick, "Photon ProbeAn Optical Fiber Time-Domain'Reflectometer," Bell Syst. Tech. J. 56 , p. 355 (1977).

15. L. A. Franks, M. A. Nelson, and T. J. Davies, "Cerenkov Pulse Dispersion in Two Low-Loss Fibers," Apply. Phys. Lett. 27, p. 205 (1975).

16. L. A. Franks, S. Lutz, and P. B. Lyons, "The Development of Long Wavelength Emitting Scintillators with Improved Decay Time Characteristics," Los Alamos Scientific Laboratory internal document, IEEE Transactions of Nuclear Science, NS-25, No. 3 (1978).

17. A. J. Lieher, Los Alamos Scientific Laboratory, private communication (1977). 